\title{
PENETAPAN KADAR ETANOL PADA ARAK JOWO YANG BEREDAR DI WILAYAH PONOROGO PADA BULAN JANUARI-MARET 2019 DENGAN METODE KROMATOGRAFI GAS
}

\author{
Yaya Sulthon Aziz ${ }^{1}$, Dian Hariyani ${ }^{2}$ \\ ${ }^{1,2)}$ Akafarma Sunan Giri Ponorogo, Jl. Batoro Katong 32 Ponorogo \\ e-mail: ${ }^{1)}$ aptgolong@gmail.com
}

\begin{abstract}
Abstrak
Latar belakang: Terdapat beberapa kasus terkait penyalahgunaan minuman keras Arak Jowo di Kabupaten Ponorogo. Saat ini banyak masyarakat sekitar yang menyalahgunakan dengan mengoplos minuman keras dengan berbagai macam jenis minuman lainnya, hingga memakan korban jiwa. Tujuan: untuk mengetahui kadar etanol pada arak jowo. Pengambilan sampel pada penelitian ini menggunakan random sampling di Polres Ponorogo. Metode: Penetapan kadar etanol dilakukan dengan menggunakan metode Kromatografi Gas dengan hasil optimasi yaitu suhu awal $50^{\circ} \mathrm{C}$ kemudian ditahan 5 menit dan ditingkatkan suhu sebanyak $200^{\circ} \mathrm{C}$ dengan waktu final 25 menit, suhu injektor yang digunakan $260^{\circ} \mathrm{C}$ dan suhu detektor $300^{\circ} \mathrm{C}$. Senyawa yang digunakan sebagai standart internal adalah n-propanol. Hasil: Pada sampel arak jowo yang diperoleh dari Polres Ponorogo mengandung etanol dengan hasil penetapan kadar etanol dari sampling sejumlah 3 botol diperoleh kadar sebanyak 42,84\%, 38,77\% dan $35,31 \%$. Simpulan dan saran: Pada arak jowo mengandung etanol yang cukup besar. Perlu dilakukan penetapan kadar untuk senyawa lain yang terdapat pada Arak Jowo yang beredar di Kabupaten Ponorogo sehingga dapat diketahui prosentase kadarnya.
\end{abstract}

Kata Kunci: Arak Jowo, Kromatografi Gas, Etanol

\begin{abstract}
Background: There are several cases related to the abuse of Arak Jowo liquor in Ponorogo Regency. Currently, many people around that abuse by mixing liquor with various other types of drinks, to take lives. Objective: to determine the ethanol content in jowo wine. Sampling in this study using random sampling at the Ponorogo Police Station. Method: Determination of ethanol content was carried out using the Gas Chromatography method with the optimization results of initial temperature of $50 \mathrm{oC}$ then held for 5 minutes and increased the temperature of $200 \mathrm{oC}$ with a final time of 25 minutes, injector temperature used $260 \mathrm{oC}$ and detector temperature of $300 \mathrm{oC}$. The compound used as an internal standard is n-propanol. Results: The sample obtained from the Ponorogo Police Station containing ethanol with the results of the determination of the ethanol content from a sampling of 3 bottles obtained levels as much as 42.84\%, 38.77\% and 35.31\%. Conclusions and suggestions: Arak Jowo contains a large amount of ethanol. It is necessary to determine the levels of other compounds found in Arak Jowo that circulate in Ponorogo Regency so that the percentage levels can be known.
\end{abstract}

Keywords: Jowo Wine, Gas Chromatography, Ethanol

\section{PENDAHULUAN}

Di Ponorogo terdapat beberapa kasus terkait penyalahgunaan minuman keras Arak Jowo. Yaitu salah satunya ditemukan penyalahgunaan minuman keras yang berujung kematian. Diduga korban meninggal karena over dosis pasca pesta minuman keras (miras) jenis Arak Jowo (Arjo) yang dioplos dengan Whisky Cola di seputaran alun alun ponorogo. Dari hasil sementara outopsi yang dilakukan 
tenaga medis RSUD Harjono, korban dinyatakan overdosis miras. Menurut Kasat Reskrim Polres Ponorogo, AKP Misrun yang diminum saat itu merupakan miras dengan kadar alkoholnya diatas 80 persen (Surya, 2013). Sesuai dengan studi kasus penulis yang bekerja sama dengan Kapolres Ponorogo pada tanggal 15 februari 2019, pada tahun 2017 ditemukan 146 kasus dan pada tahun 2018, 156 kasus penyalahgunaan minuman keras arak jowo, dan peredaran arak jowo di wilayah Ponorogo semakin tinggi.

Persyaratan kadar etanol yaitu pada golongan A sampai dengan 5\%, golongan B lebih dari 5-20\% dan golonan C yaitu lebih dari 20-55\% (BPOM, 2016). Dalam hal ini menjadi sangat penting untuk dilakukannya penelitian terhadap minuman keras khususnya arak jowo agar dapat mengetahui persen kadar etanol yang terdapat pada minuman keras Arak Jowo yang beredar di wilayah Kabupaten Ponorogo mengingat dampak etanol yang bersifat toksik atau beracun apabila dikonsumsi berlebihan. Penelitian ini dilakukan dengan metode Kromatografi gas, karena Kromatografi gas merupakan pengukuran untuk bahan-bahan yang mudah menguap dan waktu analisis yang singkat serta memiliki ketajaman pemisahan.

Penelitian ini bertujuan untuk mengetahui apakah terdapat etanol pada minuman keras Arak Jowo dan berapakah kadar etanol yang terdapat pada minuman Arak Jowo yang beredar di Kabupaten Ponorogo.

\section{METODE PENELITIAN}

Pada sampel ini digunakan teknik random sampling, dan pengambilan sampel dilakukan secara acak di Polres Ponorogo. Digunakan sampel minuman keras Arak Jowo yang sudah ditangani pihak Polres Ponorogo mulai bulan Januari, Februari dan Maret 2019. Penelitian menggunakan metode Kromatografi Gas.

Pada persiapan sampel, dilakukan destilasi pada suhu $78^{\circ} \mathrm{C}$ untuk mendapatkan etanol. Diambil kurang lebih 2,0 ml kemudian dimasukkan kedalam labu takar $10 \mathrm{ml}$. Kemudian ditambahkan n-propanol sampai batas, gojok sampai homogen. Kemudian di injeksikan sebanyak $1 \mu 1$ kedalam kromatografi gas dengan alat yang sudah di optimasi. Nilai yang diperoleh dimasukkan kedalam persamaan kurva baku etanol. Maka akan didapat kadar etanol pada sampel (Widya, 2018)

Untuk pembuatan baku etanol, Baku yang digunakan pada penelitian ini adalah etanol dengan penambahan n-propanol sebagai standart internal. Membuat larutan baku sehingga diperoleh 10\%, 20\%, $30 \%, 40 \%, 50 \%$. Kemudian ditambahkan n-propanol sebagai internal standart kurang lebih sampai batas pada masing-masing labu takar $10 \mathrm{ml}$ kemudian digojok sampai homogen. Larutan baku sebanyak $1 \mu \mathrm{l}$ dari masing-masing konsentrasi di injeksikan pada alat kromatografi gas. Setelah diperoleh kromatogram dihitung luas areanya dan dilakukan 3 kali injeksi. 
Teknik analisis pada penelitian ini adalah dengan membaca kromatogram dan menyesuaikan waktu retensi pada baku dan sampel yang diperoleh kemudian menghitung persamaan regresi pada baku dan menghitung nilai yang diperoleh sehingga diperoleh kadar etanol pada sampel arak jowo yang digunakan pada penelitian ini.

\section{HASIL DAN PEMBAHASAN}

Sampel pada penelitian ini diproses dengan menggunakan metode destilasi pada penjagaan suhu $78 \mathrm{C}^{\circ}$ dan diperoleh hasil $10 \mathrm{ml}$ pada masing masing destilat, kemudian dilakukan preparasi selanjutnya untuk di injeksikan pada kromatografi gas dengan hasil sebagai berikut.

Tabel 1. Kadar Sampel

\begin{tabular}{cccccc}
\hline No. & Nama Sampel & Area & Area & Area count & Konsentrasi \\
& & ethanol & n-propanol & & $(\%)$ \\
\hline 1. & Sampel 1 & 333737 & 115905 & 2,879401234 & 48,84 \\
\hline 2. & Sampel 2 & 303747 & 115985 & 2,618847264 & 38,77 \\
\hline 3. & Sampel 3 & 332768 & 138786 & 2,397705820 & 35,31
\end{tabular}

\section{Optimasi dan Pemilihan Standart Internal}

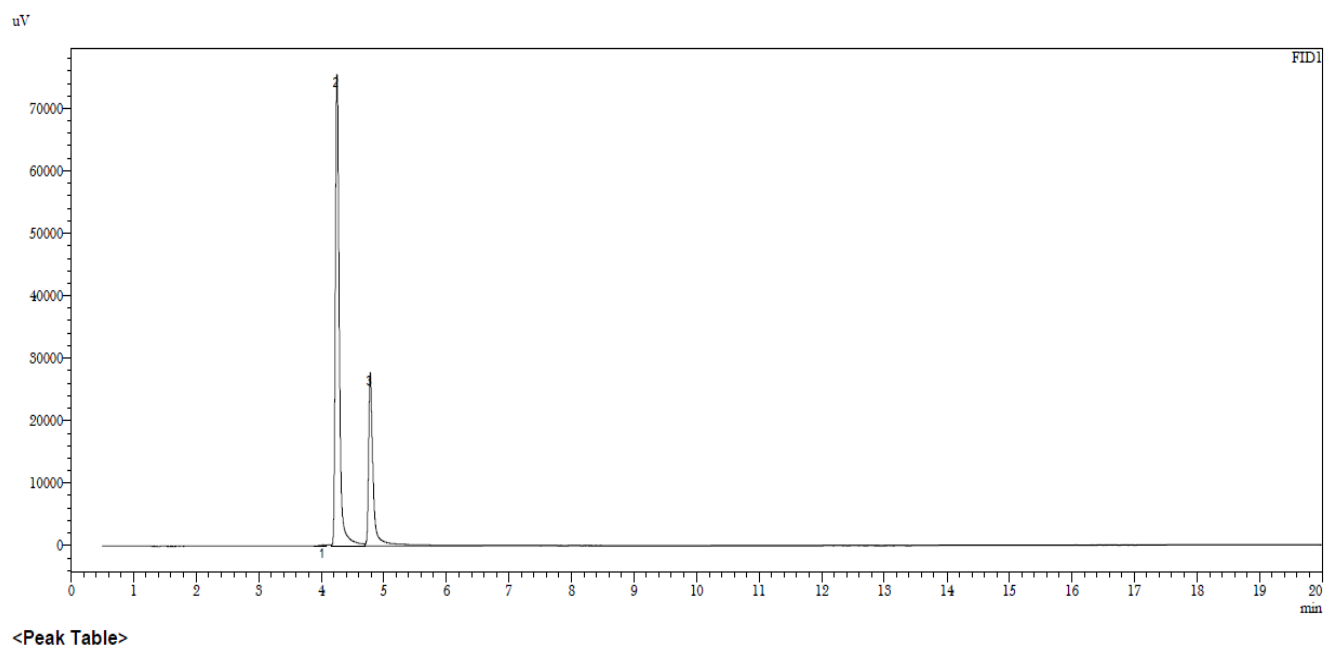

Gambar 1. Etanol Dengan Standart Internal Propanol

Pada kromatogram diatas terlihat memiliki resolusi yang cukup baik sehingga dapat digunakan sebagai pilihan standar internal. 


\section{Uji Kualitatif Sampel}

Analisis kualitatif dilakukan dengan membandingkan waktu retensi (tR) sampel dengan waktu retensi (tR) etanol dengan menggunakan standar internal propanol. Hal tersebut ditunjukkan dengan adanya (tR) sampel dengan (tR) baku pembanding yang sama. Hasil kromatogram yang diperoleh dari baku etanol dan sampel adalah sebagai berikut:

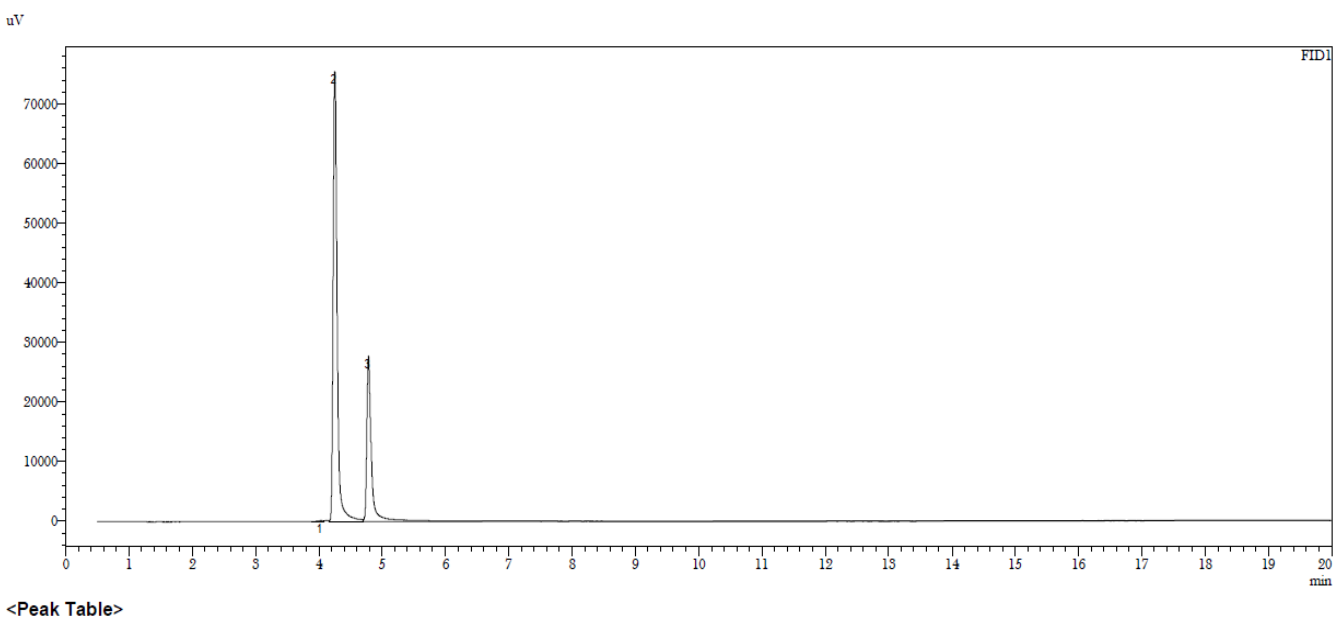

Gambar 2. Kromatografi Sampel

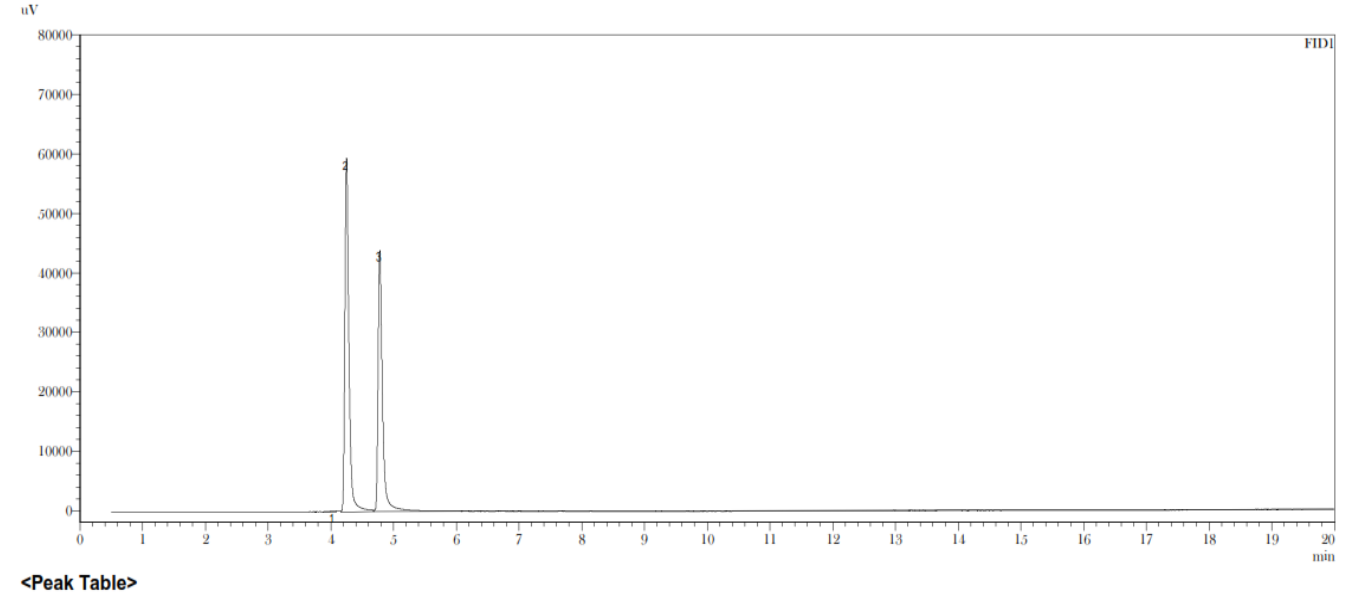

Gambar 3. Kromatografi Baku Etanol 20\%

Dari kromatogram yang dihasilkan, antara baku etanol memiliki waktu retensi yang tidak jauh berbeda dengan sampel. Waktu retensi baku etanol adalah 4,252 dan Waktu retensi sampel adalah 4,253 dengan demikian dapat dikatakan bahwa senyawa yang terdapat pada sampel yaitu etanol 
Vol. 8, No.1, Oktober 2019, hal 15-20

3. Pembuatan Kurva Baku Etanol

Tabel 2. Kurva Baku Etanol

\begin{tabular}{lclll}
\hline No & $\begin{array}{c}\text { Konsentrasi } \\
\text { standart }(\boldsymbol{\%})\end{array}$ & Area ethanol & $\begin{array}{l}\text { Area n- } \\
\text { propanol }\end{array}$ & Area count \\
\hline 1. & 10 & 138864 & 178982 & 0,775854555 \\
2. & 20 & 269030 & 169757 & 1,584794736 \\
3. & 30 & 548373 & 286778 & 1,91218643 \\
4. & 40 & 852020 & 340880 & 2,499471955 \\
5. & 50 & 1383224 & 392929 & 3,520289925 \\
\hline
\end{tabular}

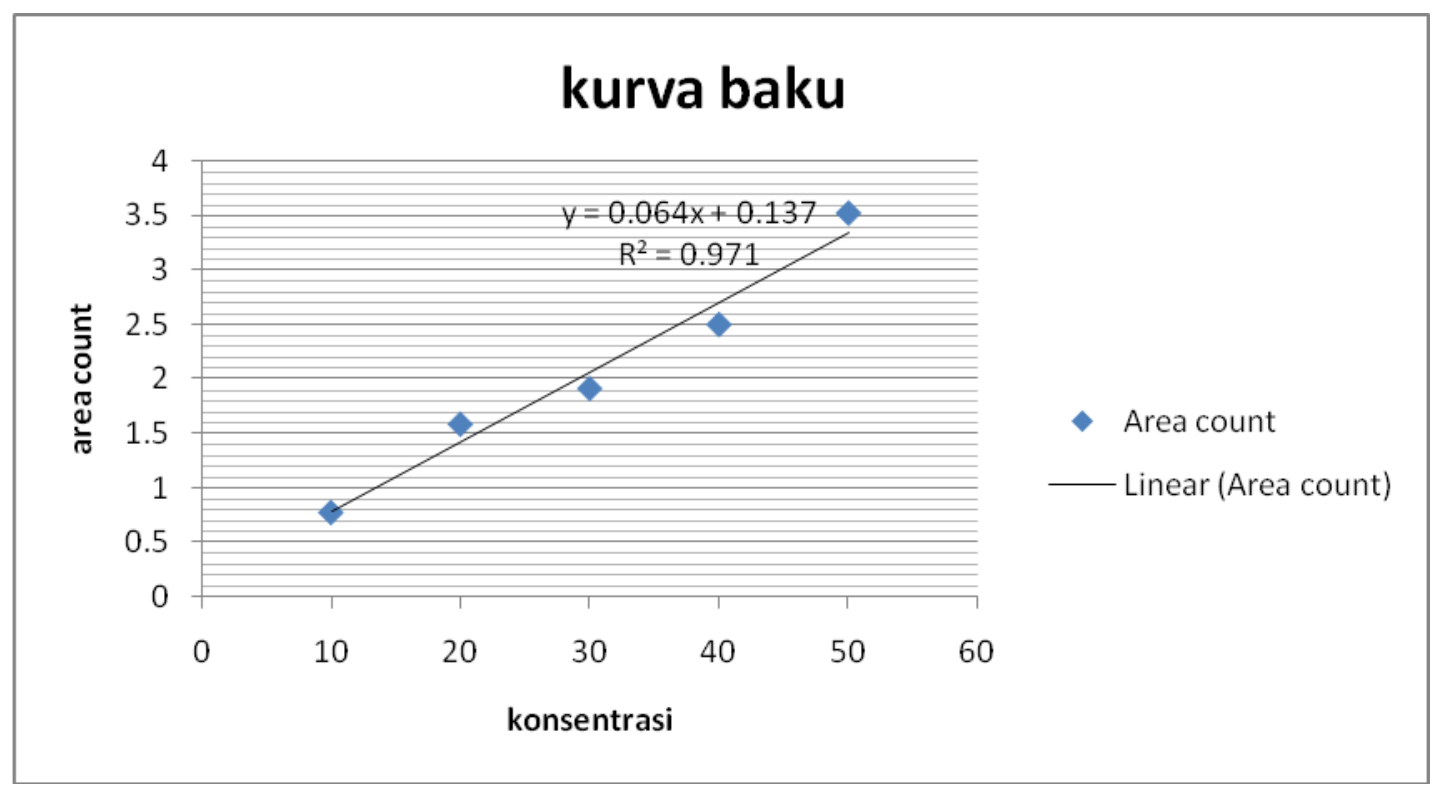

Gambar 4. Kurva hubungan antara luas area dan konsentrasi

Tabel 3. Kadar Sampel Etanol

\begin{tabular}{cccccc}
\hline No. & Nama Sampel & Area & Area & Area count & Konsentrasi \\
& & Ethanol & n-propanol & & $(\%)$ \\
\hline 1. & Sampel 1 & 333737 & 115905 & 2,879401234 & 42,84 \\
\hline 2. & Sampel 2 & 303747 & 115985 & 2,618847264 & 38,77 \\
\hline 3. & Sampel 3 & 332768 & 138786 & 2,397705820 & 35,31 \\
\hline
\end{tabular}


Berdasarkan tabel di atas diketahui bahwa setiap sampel yang dianalisis memiliki kadar yang berbeda atau tidak tetap yaitu pada sampel 1: $42,84 \%$; sampel 2: $38,77 \%$; dan sampel 3: 35,31\% Pada penelitian ini dilakukan uji kualitatif dan uji kuantitatif, Pada kromatografi gas analisis kualitatif yaitu dengan memperhatikan kromatogram yang diperoleh dengan membandingkan waktu retensi analit dengan waktu retensi standart. Jika waktu retensi standar sama dengan waktu retensi suatu komponen tertentu maka dapat diduga bahwa kedua senyawa tersebut sama. Sedangkan pada analisis kuantitatif yaitu menggunakan metode standart internal karena terdapat ketidakpastian yang disebabkan injeksi sampel, kecepatan aliran gas dan variasi keadaan kolom dapat diminimalisasi. Rasio luas puncak analit terhadap luas puncak standart internal adalah parameter analisisnya, puncak standart internal dan puncak lainnya harus terpisah dengan baik sebagai syarat keberhasilan metode ini (Skoog and Heller, 1994).

Pada uji kualitatif diperoleh waktu retensi 4,252 untuk standart dan 4,253 untuk sampel sehingga dapat dikatakan bahwa senyawa tersebut adalah etanol sedangkan untuk uji kuantitatif diperoleh kadar etanol pada sampel $1: 42,84 \%$, sampel 2: 38,77\% dan sampel 3: 35,31\%Dan sampel sesuai dengan Peraturan Kepala BPOM pada golongan C.

\section{SIMPULAN}

Pada sampel arak jowo yang diambil di Polres Ponorogo mengandung etanol 42,84\%, 38,77\% dan 35,31\% sehingga dapat dikatakan sesuai Peraturan Kepala BPOM pada golongan C.

\section{REFERENSI}

Fajar D.R,. 2013. Penetapan Kadar Etanol dan Profil Senyawa yang Terdapat dalam Hasil Produksi Ciu Rumahan Dusun Sentul Desa Bekonang Kabupaten Sukoharjo dengan Metode Kromatografi Gas. Skripsi tiak diterbitkan. Universitas Sanata Dharma Yogyakarta.

Peraturan Kepala Badan Pengawas Obat dan Makanan Republik Indonesia No.14. 2016. Tentang Standar Keamanan dan Mutu Minuman Beralkohol

Surya. 2013. Usai Pesta Miras, Siswa di Ponorogo Tewas. http://www.tribunnews.com/regional/2013/08/30/usai-pesta-miras-siswa-di-ponorogo-tewas di akses 4 februari $201921: 11$

Skoog, D.A. et al. 1994. Analiytical Chemistry An Introduction. Sixht Edition, Saunders College Publishing, USA, 507

Widya, A. 2018. Validasi Metode Dalam Penentuan Kadar Etanol Pada Arak Menggunakan Kromatografi Gas Detektor Ionisasi Nyala. Journal Of Chemistry. Vol.12, No.2 